\title{
A Study on the Awareness of Primary and Secondary School Teachers' Professional Development Evaluation in Macao
}

\author{
Sung-Yi Lee, Ziyu Zhou, Xinrui Xing \\ City University of Macau, Macau
}

\begin{abstract}
In order to promote the professional development of primary and secondary school teachers, Macao has carried out the Framework of Non-higher Education Private School Staff System, and has implemented the teachers' professional development evaluation system. Aiming to explore the current situation of the implementation of the teachers' professional development evaluation system in primary and secondary schools in Macao, this paper uses focus discussion method to interview a number of teachers so as to deeply understand the awareness of teacher professional development evaluation of primary and secondary school teachers in Macao, and analyzes and studies its content. Finally the paper finds out appropriate and reasonable solutions to the problems reflected by teachers.
\end{abstract}

Keywords-Teachers' professional development; Evaluation; Focus discussion method

\section{INTRODUCTION}

Since the new century, many countries have carried out a series of educational reforms, and the core of these reforms is to promote the professional development of teachers. And the implementation of the teachers' professional development evaluation system in Macao is intended to promote the professional development of teachers. In recent years, the teachers of primary and secondary schools in Macao also have different opinions on this system. Macao's school education is divided into non-higher education and higher education. Of which, non-higher education includes kindergartens, primary schools and secondary schools; In order to further improve the effectiveness, predictability and coordination of non-higher education policies, the SAR Government promulgated the Ten Year Plan for the Development of Non-higher Education (2011-2020) in 2011, so as to determine the direction and goal of the ten-year development of non-higher education, and plan corresponding safeguard measures to mobilize the power of the whole society to jointly promote the development of education [1].

After absorbing valuable opinions from all sectors of society, especially the education sector and making a number of revisions, and after the discussion of the Executive Council and the Legislative Council, the Legislative Council passed the Framework of Non-higher Education Private School Staff System (hereinafter referred to as the Private Framework) on February 29. The implementation of Private Framework will further enhance the professional development and career security of teaching staff, thus establishing a high-quality teaching staff team. It is especially reflected in several aspects. The first is to set the requirements for teaching staff and establish their professional expertise; the second is to set up a career system for the teaching staff, and set up the promotion conditions of each grade, so as to promote the professional development of the teaching staff; the third is to reduce the number of teaching hours of the teaching staff, and let them have more time to take care of the different needs of students, and thus improving the teaching and learning efficiency of teachers and students; the fourth is to guide the rational use of public funds in schools, to ensure that the teaching staff get reasonable salary treatment, so as to further stabilize the teaching staff team; the fifth is to strengthen the retired welfare of the teaching staff, so that they can get the due guarantee for their retirement life [2].

\section{THE IMPLICATIONS OF TEACHERS' PROFESSIONAL DEVELOPMENT EVALUATION}

The professional development of primary and middle school teachers is the starting point and core guarantee for the improvement of the quality of basic education. The formulation and implementation of the primary and secondary school teachers' professional development evaluation system is a prerequisite for the promotion of primary and secondary school teachers' professional development. Therefore, the professional evaluation system of primary and secondary school teachers is a major issue in teacher education academic research and teacher training and development planning [3]. And how to establish a perfect teacher professional development evaluation system has always been a headache for schools and related departments. Rao Jianwei [4] believes that the concept of teacher professional evaluation basically regards teacher as a professional job, while a teacher is an individual who continues to develop. It can improve its professional level and professional performance through a continuous learning and inquiry process. Zhang Derui[5] believes that teachers' professional development evaluation is to collect teachers' teaching performance data through teachers' self-analysis, peers' classroom observation, and students' teaching reaction, and then encourages teachers and colleagues to set up professional development plans and implement them on the basis of mutual trust and cooperation, so as to promote the professional development of teachers. Therefore, it is a typical 
formative, developmental and diagnostic teacher evaluation, but also a professional and service-oriented teaching guidance work.

\section{CURRENT Situation OF TEACHERS' PROFESSIONAL DEVELOPMENT AT HOME AND ABROAD}

Many advanced countries have already promulgated some laws and regulations on education, promulgated relevant teacher professional development standards and evaluation methods. New York of the United States promulgated the professional development standard of primary and secondary school teachers in 2009. The professional development standard of primary and secondary school teachers in New York pay more attention to the planning and monitoring of teachers' professional development from the perspective of dynamic and process. The standard has ten cores: teachers' professional development design, subject knowledge and high quality teaching, research based professional learning, cooperation, multiple learning, student learning environment, parents, family and community participation, data based teachers' professional development practice, technology and evaluation [3]. The White Papar: Teacher Quality published by England in 1983 also emphasized the need to make formal evaluation of the teaching performance of primary and secondary school teachers, so as to ensure that teachers' professional competence can be promoted and developed; and the Teacher Evaluated Regulation officially announced in 1991 also has detailed provisions on the purpose, method, cycle, supervision and evaluation of teacher evaluation [6].

In our country, although there is no clear evaluation system for teachers' professional development, the Teacher Law, which began to implement in 1994, clearly stipulates that: "Teachers are professional personnel who perform educational and teaching duties, undertake the mission of teaching and educating people, cultivating socialist construction and successors, and improving national quality. Teachers should be loyal to the people's education cause." This is a legal recognition of the professional status of teachers in China. In 1995, the State Council promulgated the Measures for the Implementation of the Teacher Qualification Ordinance, and the teacher qualification system began to be implemented in the whole country. In 2000, the first authoritative file that classifies occupations scientifically, Occupational Classification of the People's Republic of China, divided teachers into "teacher professional and technical personnel". All these provide a basic system guarantee for our country to realize the professional development of primary and secondary school teachers and promote the professionalization of teachers [7].

\section{RESEARCH METHODS AND STEPS}

This section includes two parts: research methods and research steps. The research method is to collect data and conduct focus group discussion based on the data. The research steps are divided into five stages: read the relevant literature from the preparatory stage of the interview, compile the outline of the interview, prepare the equipment needed for the focus discussion, conduct focus group discussion and finally analyze its content to draw a conclusion, and summarizes the assessment of the primary and secondary school teachers in Macao on the implementation of teachers' professional development evaluation in Macao at the present stage.

\section{A. Research methods}

This study will adopt the focus discussion method to carry on the research. The focus group interview is a way to collect information in qualitative research. This study is carried out mainly through focus group discussion on several primary and secondary school teachers in Macao. Through collecting, sorting and summarizing the interview records, school data and policy files issued by the government on this university, the author obtains the views of primary and secondary school teachers in Macao on the implementation of the teachers' professional development evaluation system

\section{B. Research steps}

This study aims to explore the views of primary and secondary school teachers in Macao on the implementation of teachers' professional development evaluation system, and interview several primary and secondary school teachers in Macao by using the focus discussion method, analyze the results and find out the answers, and find out the countermeasures according to the answers.

\section{Research issues are as follows:}

- What do you think of teachers' professional development evaluation in schools?

- What are the subsequent applications and related results of the school for the evaluation results?

- What influence do you think it has on you to participate in the teachers' professional development evaluation promoted by the school?

- The research steps of this study include collecting literature and materials, focus group discussion and other stages:

\section{Collect literature}

Collect the relevant literature and materials for professional development evaluation of teachers through various major websites, such as Macao Education and Youth Bureau, Macao Statistics and Census Bureau and library books.

\section{E. Determine interview outline}

Conduct interviews with scholars and experts. This study adopts the focus discussion method and purposive sampling. In actual interviews, the interview outline is taken as the basic framework and direction of data collection, and the interviewees answer in an open manner. 


\section{F. Prepare focus discussion}

Before the interview, prepare all the equipment to be used in the interview, such as recording pen, pen, paper, confidentiality undertaking, and seeking locations and interviewees and so on.

\section{G. Focus discussion method}

According to the purpose of the study, a team of 18 experts and scholars meeting the specific conditions was selected to conduct 3 focus group discussions. The focus group discussion method is helpful for inviting people from different backgrounds for the focus issues, and creating a free group interaction atmosphere, so that members of the participating group can fully express their experiences, views or opinions on the topics discussed by the researchers. A variety of views or opinions on the subject; Interviews with the interviewees were conducted, and the contents of the interviews were collated and analyzed. It is helpful for inviting people from different backgrounds to focus on issues. Interview the interviewees and arrange and analyze the content after the interview.

\section{RESEARCH FINDINGS}

Based on the research questions and the results of the focus discussion, three major research findings are summarized respectively:

\section{A. Primary and secondary schools carry out the evaluation of teachers' professional development, common view of teachers}

The views of experts and scholars are as follows:

A1. It helps to enhance teachers' professional development and enhance teachers' professional dedication.

A2. It allows students to give some suggestions to their teachers because they are most directly aware of the teacher's teaching quality.

A3. Two teachers at each grade will be evaluated and it will not be repeated next year, and two others will be evaluated. It will be circulated after all teachers are evaluated.

A4. Schools use different methods and standards, which is easy to cause loopholes. It is formalistic, but a bitter is better than nothing, so it is a good start.

A5. The intention is good, but we should develop a suitable evaluation method for front-line teachers, so as not to overburden the teachers.

A6. The evaluation of teachers' professional development in schools is helpful to the growth of teachers' professional quality. The government should strengthen the evaluation mechanism and let the school have corresponding guidance to coordinate the work.

A7. It enables us to understand teachers' professional level and teaching mode. It will be better if various aspects of the teachers' teaching are evaluated.

A8. It can promote teachers' introspection and adjustment of teaching, encourage teachers to learn and help teachers' professional development to some extent. But because of time and manpower limit, the evaluation may be less comprehensive or objective.

A9. By assessing teachers' professional performance, teachers can reflect and review teaching gains and losses anytime and anywhere, which is beneficial to their professional development.

\section{B. Subsequent application of the evaluation results of the school and related results}

The views of experts and scholars are as follows:

B1. It can open personal teaching plans and let colleagues learn from each other.

B2. The content of evaluation can be simplified, so that teachers do not have to face the pressure of evaluation.3. The peers can integrate teaching plans.

B3. It can observe the teacher's performance before and after and give feedback.

B4. We can have a deeper understanding of the teacher's professional growth.

B5. The evaluation equipment can be adjusted.

B6. The post performance is not effective until it is evaluated and assessed.

B7. Most of the teachers who failed to meet the criteria are finally rated satisfactory.

B8. It has little effect on teachers who feel good about themselves.

B9. Provide advice to teachers.

B10. Adjust the teaching arrangement.

\section{The impact of school driven teachers' professional development evaluation on teachers}

The views of experts and scholars are as follows:

$\mathrm{C} 1$. The teaching plan is designed carefully, but the effect of classroom teaching fails to catch up with it, which will affect the school's impression of the teacher.

C2. It is no harm to look at a few lessons, but it is too timeconsuming to design lesson plans.

C3. The lesson plans are specially designed only when participating in competition, because the work is busy at ordinary times.

C4. Self-inspection of teaching quality can be made and objective assessment can be obtained.

C5. Too many assessments will affect teachers' work and increase their pressure.

C6. Members of the evaluation team can objectively review their teaching strategies and on-the-spot teaching quality, etc., and the teachers can make introspection.

C7. Teachers can understand their teaching and improve their profession, so as to keep pace with the times. 
C8. Teachers can know what needs to be improved.

C9. It can strengthen the communication between the school and the teacher.

C10. It can improve the effectiveness of teaching and learning.

C11. It can enhance the teachers' enthusiasm of participating in profession related study activities.

C12. Teachers can think more and adjust the teaching related design and effectiveness.

\section{CONCLUSIONS AND SUGGESTIONS}

Macau has implemented the system and measures to promote the professional development of teachers for only a few years, and the evaluation system on the professional development of teachers has just begun. Although the experience of many successful regions and countries has been learned, the actual situation varies from region to region, and there are more or less different problems. However, the implementation of teachers' professional development evaluation system is worthy of recognition and promotion, and it is conducive to the teachers' introspection and professional development. Teachers in primary and secondary schools in Macao think so. They think that the implementation of teachers' professional development evaluation in schools will help others to test their own teachers' professional level, and meanwhile, they will also conduct introspection, provide relevant suggestions for teachers, make up for their deficiencies, and help teachers to grow professionally. This helps to enhance teachers' awareness of enhancing their professional quality and strengthen communication between schools and teachers. The conclusions are as follows:

(1) Teachers in primary and middle schools in Macao attach great importance to the evaluation activities and are willing to accept challenges, and they have a high willingness to grow. Therefore, it is suggested that education institutions in primary and secondary schools can use the winter and summer holidays to hold more teacher assessment studies, workshops or growth promotion groups to learn evaluation procedures and stimulate teachers' motivation to improve, so as to improve teachers' willingness to participate in the teachers' professional development evaluation.

(2) Select senior teachers to guide backward teachers, and share personal experience through related meetings and informal occasions, to guide the backward teachers and improve their cognition, attitude and willingness to participate in the teachers' professional development evaluation.

(3) Formulate standards for the teachers' professional development evaluation, and list in detail the methods, modes and contents of the standards. The principal or director can encourage colleagues to formulate the standards through formal meetings or personal communications, for more teachers to know more about evaluation activities in the future, and as a reference for education teaching, so as to understand the purpose of teachers' evaluation and improve the teachers' cognition of professional evaluation and their participation attitude, and get rid of the difficulties in evaluation activities.
(4) Encourage teachers to participate in evaluation, and improve the knowledge of class management, which is helpful to solve the difficult situation of class management, improve teachers' cognition of the feasibility of professional development evaluation, cultivate teachers' good participation attitude and increase their willingness to participate.

(5) Improve the evaluation method of teachers; achieve self-growth through the evaluation, rather than thinking of it as an additional burden and reducing the recognition of the importance of teachers' professional evaluation activities. Therefore, it is suggested that teachers should help themselves to grow and improve their professional image, and improve their own evaluation methods.

Although the original intention of the establishment of the system is good and it also has some effect in the process of implementation, it has a certain influence on the life of primary and secondary school teachers in Macao: it increases the workload of teachers and lets many teachers have no time to take care of the trivia in their homes, and too many evaluations have brought pressure to the teachers; teachers' professional development evaluation cannot be completely fair and just, and many teachers feel unjust, and the schools have various methods and standards, which have brought trouble to teachers. In order to change this situation, the following suggestions are proposed:

\section{A. Establish a more equitable and fair evaluation mechanism for teachers' professional development}

To sum up, many teachers reflect that the school teacher professional evaluation system has some unfair and unreasonable places. In order to avoid teachers knowing each other or forming cliques in the process of evaluation, the evaluation work can be issued to third parties, such as a department of the Education and Youth Bureau, to manage the teachers' professional development evaluation work, and the system standard should be unified, to facilitate management operation and implementation, and also avoid unnecessary troubles.

\section{B. Streamline the number of evaluations}

Too much assessment not only brings great workload to teachers, but also creates great pressure on the spirit. The purpose of the evaluation system is good, in order to promote the professional development of teachers and raise teachers' awareness of continuing professional education. We should simplify the number of evaluations, and improve the quality of each evaluation, so that we can know where the weaknesses lie from each evaluation, and make corrections and improvements.

\section{Enrich evaluation method}

Neither the self-evaluation of the teacher nor the other comments from colleagues and principals are as profound as those of students taught by the teacher. These students are the direct beneficiaries of the courses taught by the teacher, and they can feel the teacher's teaching quality best. In addition to evaluation of other teachers, students' evaluation of the work of teachers can be added. It is possible that the advice given by these students is the most pertinent. 


\section{REFERENCES}

[1] Macao Education and Youth Bureau. Ten Year Plan for Non-higher Education Development (2011-2020); Derived from December 11, 2017, http://portal.dsej.gov.mo/webdsejspace/internet/Inter_main_page.jsp?id= 21211.

[2] Macao Education and Youth Bureau. Framework of Teaching Staff System for Private Schools of Non-higher Education is approved by the Legislative Council. Derived from December 12, 2017, http://portal.dsej.gov.mo/webdsejspace/addon/allmain/msgfunc/Msg_fun clink_page.Jsp?Msg_id=22658\&.

[3] Li Hengqing, Zeng Ming. A Brief Discussion on the Standard of Professional Development of Primary and Secondary School Teachers in the United States: Taking New York as an Example [J]. Journal of Inner Mongolia Normal University (education science edition), 2015, 28(04):50-53.

[4] Rao Jianwei (1996). The Specialization of Education and the Implementation of Educational Practice. In the Republic of China Normal Education Society (Editor-in-chief), the major of education, 183-209. Taipei: the Academy of Teachers University.

[5] Zhang Derui. The Development, Promotion, Research and Implementation Prospect of the Formative Teacher Evaluation System. [J]. Primary Education Journal, 2006(23):1-26.

[6] Wu Zhenyi. A Discussion on the Implementation of Teacher Evaluation System in Primary and Secondary Schools in China [J]. Teachers' friend, 2000(41):2-9.

[7] Song Guangwen, Miao Hongxia. On the Realization of Primary and Secondary School Teachers' Professional Development in China [J]. Journal of Ji'nan Institute of Education, 2004(04):15-19+36. 